\title{
ARTIGO ORIGINAL \\ Implantação do Score de deterioração clínica (MEWS) em um hospital privado da cidade do Rio de Janeiro e seus respectivos resultados
}

Ellen Simone Vasconcelos Cipriano*, Bruna de Sousa Salgado**, André Nobre de Oliveira, M.Sc. ${ }^{* *}$, Beatriz Gerbassi Costa Aguiar, D.Sc. ${ }^{* * *}$

*Pós-graduanda em enfermagem hospitalar com ênfase em saúde do idoso no formato de residência, pela Faculdade Adventista da Bahia (FADBA), Enfermeira Plantonista da Unidade de Terapia Intensiva do Hospital Adventista Silvestre - Unidade Itaboraí, Rio de Janeiro, ${ }^{\star *}$ Pósgraduanda em enfermagem hospitalar com ênfase em saúde do idoso no formato de residência, pela FADBA, Enfermeira Plantonista da Unidade de Internação do Hospital Adventista Silvestre, Unidade Cosme Velho, Rio de Janeiro/RJ, ${ }^{* * *}$ Pós-graduado em Docência do Ensino Superior, pelo UNASP, Mestrando em Enfermagem pela Universidade Federal do Estado do Rio de Janeiro (UNIRIO), Gerente de Enfermagem do Hospital Adventista Silvestre, Unidade Cosme Velho, Rio de Janeiro/RJ, ${ }^{\star * \star *}$ Professora Associada do Dpto de Enf. Médico-Cirúrgica da Escola de Enfermagem Alfredo Pinto da Universidade Federal do Estado do Rio de Janeiro e Professora do Programa de Mestrado em Enfermagem da Universidade Federal do Estado do Rio de Janeiro, Rio de Janeiro/RJ

Recebido em 19 de setembro de 2017; aceito em 19 de outubro de 2017.

Endereço de correspondência: André Nobre de Oliveira, Depto de Enfermagem do Hospital Adventista Silvestre, Ladeira do Ascurra, 274, Cosme Velho, 22241-220 Rio de Janeiro RJ, Email: andre.nobre@hasilvestre.org.br; Ellen Simone Vasconcelos Cipriano: simone.ellen@yahoo.com.br; Bruna de Sousa Salgado: ktussa@hotmail.com; Beatriz Gerbassi Costa Aguiar: residenfermagem@unirio.br

\section{Resumo}

Objetivo: Analisar a implantação do Escore de Deterioração Clínica (MEWS) em um hospital privado filantrópico da cidade do Rio de Janeiro/RJ. Material e métodos: Trata-se de um estudo documental realizado em um hospital privado, filantrópico no Rio de Janeiro. A coleta de dados foi realizada nos registros da comissão de óbitos e livro de registro da supervisão de enfermagem. Foram incluídos 101 registros de pacientes que os supervisores de enfermagem acompanharam o desfecho com o escore de MEWS no livro de registro de enfermagem no período de janeiro a julho de 2016. Os dados obtidos foram agrupados em frequências simples e porcentagens e apresentados em forma de gráficos e tabelas. Resultados: De acordo com os dados coletados, foram predominantes: o sexo feminino, a faixa etária acima de 60 anos, 0 registro de $M E W S>5$, e o desfecho relacionado à transferência para unidades de terapia intensiva. Conclusão: O MEWS é uma excelente ferramenta para avaliar e prevenir deterioração clínica hospitalar, analisar a qualidade da assistência e a segurança do paciente e contribui para a tomada de decisão para prevenção de deterioração clínica do paciente.

Palavras-chave: Enfermagem, emergência, sinais vitais.

\footnotetext{
Abstract

Implantation of the clinical deterioration score (MEWS) in a private hospital of Rio de Janeiro and its respective results

Objective: To analyze the implantation of the Modified Early Warning Score (MEWS) for clinical deterioration in a private philanthropic hospital in the city of Rio de Janeiro. Methods: This is a documentary study conducted at a private, philanthropic hospital, whose data collection was performed in the records of the Death Commission and Nursing Supervision Record books. A total of 101 patient records were included and the nursing supervisors followed the MEWS score in the nursing record book from January to July 2016. Data were grouped into simple frequencies and percentages and were presented in the form of charts and tables. Results: According to the data collected, it was predominant: the female gender, the age group above 60 years, the MEWS record $>5$, and the outcome related to the transfer to intensive care units. Conclusion: The MEWS is an excellent tool for evaluation and prevention of clinical deterioration in hospital, for analyzing quality of care and patient safety, and contribute to the decision making to prevent clinical deterioration of the patient.
} 
Key-words: Nursing, emergency, vital signs.

\begin{abstract}
Resumen
Implantación del Score de deterioro clínico (MEWS) en un hospital privado de la ciudad de Rio de Janeiro y sus respectivos resultados

Objetivo: Analizar la implantación del Escore de Deterioración Clínica (MEWS) en un hospital privado filantrópico de la ciudad de Río de Janeiro/RJ. Material y métodos: Se trata de un estudio documental realizado en un hospital privado, filantrópico en Río de Janeiro. La recolección de datos fue realizada en los registros de la comisión de óbitos y libro de registro de la supervisión de enfermería. Se incluyeron 101 registros de pacientes que los supervisores de enfermería acompañaron el desenlace con el puntaje de MEWS en el libro de registro de enfermería en el período de enero a julio del 2016. Los datos obtenidos fueron agrupados en frecuencias simples y porcentajes y presentados en forma de: gráficos y tablas. Resultados: De acuerdo con los datos recolectados, fueron predominantes: el sexo femenino, el grupo de edad superior a 60 años, el registro de MEWS > 5, y el desenlace relacionado con la transferencia a unidades de terapia intensiva. Conclusión: EI MEWS es una excelente herramienta para evaluar y prevenir el deterioro clínico hospitalario, analizar la calidad de la asistencia y seguridad del paciente, y contribuye a la toma de decisión para prevención de deterioro clínico del paciente.
\end{abstract}

Palabras-clave: Enfermería, emergencia, señales vitales.

Introdução

As instituições hospitalares são caracterizadas por serem estruturas extremamente complexas, com vários atores e interesses diferentes. Com o crescimento da procura por uma assistência progressivamente mais complexa, o atendimento foi sendo segmentado em áreas específicas dos conhecimentos profissionais e áreas físicas. Estes departamentos e serviços são interdependentes nas suas demandas e nos seus resultados em que o bom funcionamento é essencial para concretizar os ideais de segurança e atendimento centrado no paciente [1].

É possível afirmar que os fluxos de atendimento e os processos de comunicação deficitários entre diversas áreas e profissionais envolvidos na assistência provocam atrasos na resolução dos problemas, descontentamento dos usuários e, em alguns casos, desfechos clínicos indesejados. Isto é essencialmente importante quando tratamos de pacientes gravemente enfermos ou com quadro clínico descompensado, em que a tomada de decisão irá interferir diretamente no resultado final do atendimento [1].

Atualmente, os hospitais de grande porte estão investindo em profissionais qualificados para atuarem em unidades abertas e emergência, por se tratarem de setores em que 0 paciente possui uma necessidade de cuidados mais precisos. Por isso, faz-se necessário que profissionais que atuam nestas áreas estejam altamente treinados e permanentemente atentos na busca por sinais clínicos que indiquem gravidade ou descompensação clínica. Nota-se a busca constante por métodos que sejam capazes de reverter ou evitar graves consequências aos pacientes internados, no intuito de alcançar o sucesso terapêutico [1].

De todas as intercorrências ocorridas nas unidades hospitalares, a parada cardiorrespiratória (PCR) é a de maior gravidade. Mesmo com atendimento especializado, organizado e rápido, o índice de mortalidade hospitalar relacionado à PCR é até $85 \%$, constituindo a condição de emergência mais severa que pode acometer um ser humano [1].

A PCR é definida como a interrupção das atividades respiratórias e circulatórias efetivas. A intervenção para reverter o quadro tem como princípios fundamentais a aplicação de um conjunto de procedimentos para restabelecer a circulação e a oxigenação [2].

Entende-se que o conhecimento científico acerca do manejo da PCR acarreta uma maior capacitação dos profissionais de saúde, assim como da instituição hospitalar, no desempenho de uma assistência mais qualificada no suporte básico e avançado de vida [3]. Vale ressaltar que a capacitação necessária aos profissionais da equipe de enfermagem, por exemplo, pode ser obtida por meio de treinamentos frequentes no ambiente de trabalho [4].

No hospital de estudo, existe um grupo de resposta rápida de atendimento à parada cardiorrespiratória, o qual é acionado através de um código sonoro, situando o local onde está ocorrendo o evento. Sabe-se que "muitas estratégias têm sido realizadas com o objetivo de diminuir os riscos para estes pacientes irem a óbito ou evoluírem para PCR" [5].

Atualmente, existem inúmeros scores para a área da saúde com a finalidade de pontuar e detectar sinais de risco e deterioração de pacientes em unidades de internação. 
Entre eles, temos o score de MEWS (Modified Early Warning Score) que tem sido amplamente adotado como uma ferramenta clínica útil para identificar os pacientes em risco de deterioração que requerem uma maior atenção [6].

O MEWS é uma pontuação somada de dados fisiológicos rotineiramente registrados para cada paciente, que inclui aferição de pressão arterial sistólica, frequência cardíaca, frequência respiratória, temperatura corporal, nível de consciência, gerando pontuações (scores) conforme as alterações que o paciente estiver apresentando no momento, comparado com os valores normais de cada sinal vital, conforme apresentado na tabela I. É uma ferramenta simples, rápida, que pode ser aplicado pela equipe de enfermagem e os diferentes valores dos sinais vitais aferidos são convertidos para scores que, depois de somados, traduzem diferentes graus de risco. O parecer dos dados obtidos determina o estado clínico do paciente para que sejam adotadas medidas que previnam a PCR [7].

Tabela I - Escore de Alerta Precoce Modificado - Modified Early Warning Score (MEWS).

\begin{tabular}{llllllll}
\hline Escores & $\mathbf{3}$ & $\mathbf{2}$ & $\mathbf{1}$ & $\mathbf{0}$ & $\mathbf{1}$ & $\mathbf{2}$ & $\mathbf{3}$ \\
\hline PAS (mmHg) & $\leq 70$ & $71-80$ & $81-100$ & $101-199$ & & $\geq 200$ & \\
FC (bpm) & & $\leq 40$ & $41-50$ & $51-100$ & $101-110$ & $111-129$ & $\geq 130$ \\
FR (ipm) & & $\leq 8$ & & $9-14$ & $15-20$ & $21-29$ & $\geq 30$ \\
Temperatura & & $\leq 34,9$ & & $35-38,4$ & & $\geq 38,5$ & \\
$\begin{array}{l}\text { axilar } \\
\text { Nível de }\end{array}$ & & & & alerta & confuso & $\begin{array}{l}\text { Resposta } \\
\text { à dor }\end{array}$ & inconsciente \\
consciência & & & & & & & \\
\hline
\end{tabular}

A partir dos sete parâmetros é calculado um escore global (figura 1) e quando uma pontuação limiar é atingida ativa ações que têm por objetivo garantir intervenções adequadas para os pacientes, minimizando o risco de deterioração do paciente. Vale destacar que MEWS é um método auxiliar, não substituindo a avaliação clínica [8].

Qualquer pontuação acima de zero indica que o paciente deve receber uma maior vigilância, justificando um acréscimo na frequência das observações [9]. O MEWS tem por objetivo facilitar a comunicação rápida entre a equipe de enfermagem e médica.

Esta escala de deterioração clínica é de suma importância nas unidades de internação, pois as alterações fisiológicas que transpõem a deterioração clínica podem denunciar precocemente os pacientes potencialmente críticos, alertando para a necessidade de monitorização hemodinâmica. Portanto, a demora na identificação da desestabilização desses quadros clínicos implica no atraso de intervenção e, assim, no aumento da mortalidade hospitalar por PCR.

O elemento-chave para o apropriado reconhecimento e tratamento do paciente em deterioração é a documentação precisa e atenta de sinais vitais, a capacidade de interpretar gravações de sinais vitais, atuar rapidamente sobre tendências de deterioração e disponibilidade de uma equipe de emergência médica [10]. Nota-se que escores de alerta precoce utilizados à beira do leito constituem uma ferramenta simples na identificação de pacientes com risco iminente de morte, possibilitando reverter a deterioração clínica do paciente.

Na vivência de Enfermeiros Residentes em uma instituição privada do Rio de Janeiro, notou-se que o MEWS é relevante no âmbito hospitalar, pois esta escala permite uma melhor comunicação, oferecendo autonomia profissional aos enfermeiros, melhorando a relação entre os profissionais, repercutindo no melhor atendimento ao paciente, prevenindo riscos de PCR em unidades de internação, detectando precocemente a necessidade de transferir pacientes para unidades de tratamento intensivo, bem como avaliar o desfecho de seu tratamento. Tendo uma importância muito significativa na sociedade contemporânea, pois o MEWS parece ter grande repercussão minimizando as PCR e diminuindo óbitos após transferências para Centros de Terapias Intensivas.

No processo de implantação do MEWS no hospital em estudo, o estímulo inicial ocorreu durante algumas visitas anteriores realizadas pela Organização Nacional de Acreditação (ONA). Na primeira visita foi notada a necessidade de utilizar uma maneira de avaliar a deterioração clínica do paciente. Foi realizada uma reunião com a gerência de enfermagem, profissionais do setor de qualidade e gerência médica do hospital, a fim de traçar estratégias para avaliar a deterioração clínica do paciente, e acordaram que seria utilizado o MEWS. A partir de então houve um aprofundamento sobre assunto e foi elaborado um protocolo para a implantação. No primeiro ano, 2014, após a implantação não se obteve muito 
sucesso. Chegou-se à conclusão de que os profissionais deveriam ser estimulados a entender o conceito e os motivos deste processo.

Treinamentos foram realizados em cada setor sobre a importância da implantação, o desfecho clínico do paciente com e sem a utilização do MEWS e os profissionais de enfermagem inseridos nesse processo. Compreendeu-se que deveria ser enfatizada a relevância do envolvimento do técnico de enfermagem supervisionado pelo enfermeiro. A partir de então, a importância do enfermeiro, neste processo, foi essencial através do seu gerenciamento nas unidades, obtendo sucesso em casos isolados e o resultado deste trabalho contribuiu na difusão do projeto. Anteriormente, a pontuação estabelecida para acionar 0 médico era MEWS a partir de 5. Contudo, após uma plenária realizada no hospital, na qual foi abordado que quanto menor a pontuação acionar o médico, melhores serão os resultados no desfecho clínico do paciente, o ponto de corte foi modificado para 3. Vale ressaltar que 0 MEWS é dinâmico, porque depende do perfil dos pacientes, da criticidade dos mesmos.

O estudo pretende contribuir para a reflexão da utilização do MEWS, enfatizando a eficácia do MEWS, como ferramenta clínica, capaz de detectar precocemente os sinais de deterioração clínica, servindo como fonte de pesquisa no âmbito da saúde, norteando a prática clínica, sendo assim de relevância para os acadêmicos e profissionais de saúde.

O objetivo do estudo é analisar a implantação do Escore de Deterioração Clínica em um hospital privado filantrópico da cidade do Rio de Janeiro/RJ.

\section{Material e métodos}

Trata-se de um estudo documental que "se vale de materiais que não receberam um tratamento analítico, ou que ainda podem ser reelaborados de acordo com os objetos da pesquisa" [11]. De modo geral, constitui um fim em si mesmo, com objetivos bem mais específicos, envolvendo muitas vezes teste de hipóteses; pode exigir a consulta aos mais diversos tipos de arquivos públicos e particulares; podem aparecer sob os mais diversos formatos, tais como fichas, mapas, formulários, cadernetas, documentos pessoais, cartas, bilhetes, fotografias, fitas de vídeo e discos [12].

A pesquisa foi realizada em um hospital privado filantrópico, localizada na cidade do Rio de Janeiro/RJ. A coleta de dados sucedeu de forma investigativa nos registros da comissão de óbitos e livro de registro da supervisão de enfermagem.

Foram incluídos 101 registros de pacientes que os supervisores de enfermagem acompanharam o desfecho com o escore de MEWS no livro de registro de enfermagem no período de janeiro a julho de 2016.

Com base nos resultados, os dados foram compreendidos de forma sistemática, utilizando, como ferramenta computacional para a formulação de gráficos e tabelas, o Microsoft Excel.

Vale destacar que o presente estudo atendeu as recomendações previstas na resolução 466/12 do Ministério da Saúde (MS), aos princípios e aspectos éticos. O projeto de pesquisa foi submetido e aprovado pelo Comitê de Ética em Pesquisa da Faculdade Adventista da Bahia (FADBA), com certificado de aceitação e apreciação ética ํo 1.817.435.

Resultados

Considerando os 101 registros de pacientes, coletados no livro de registro dos supervisores de enfermagem, verificou-se uma média de 15 registros mensais, no período entre janeiro e julho de 2016. Esta foi a meta do hospital (Gráfico I) para a quantidade de registro mensais do livro de MEWS. 


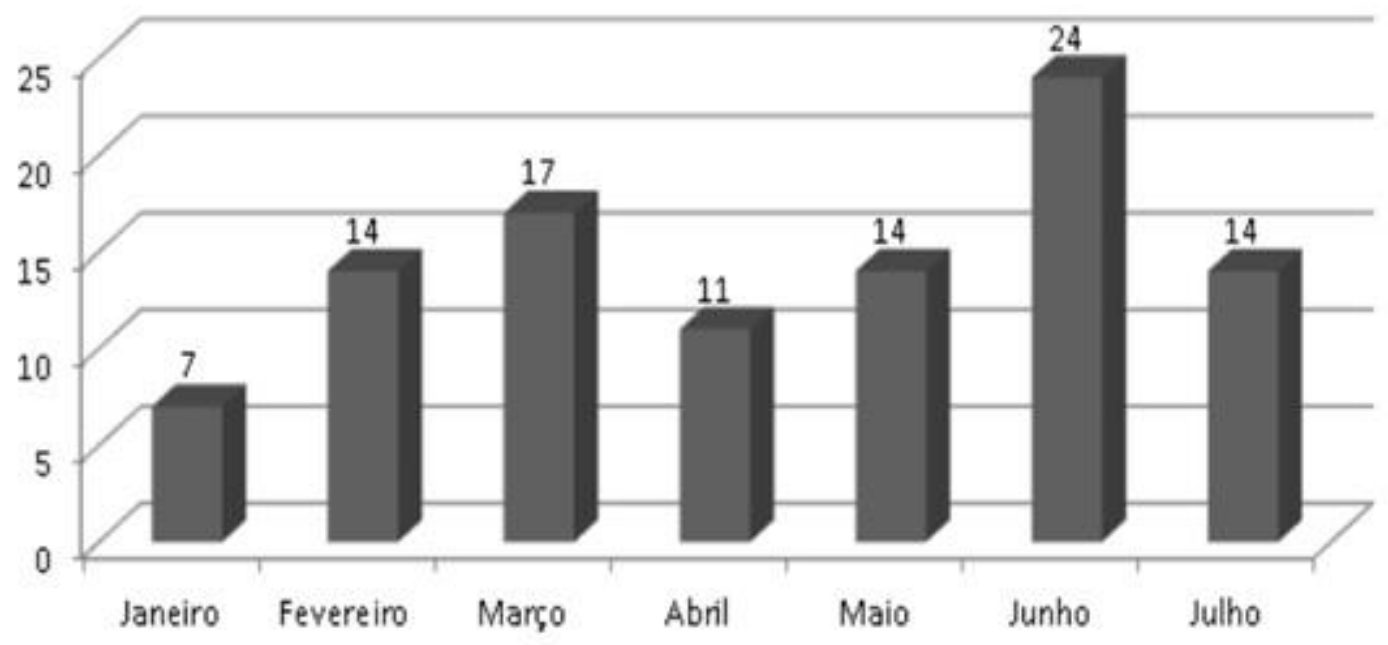

Gráfico I - Total de registros analisados por mês, tendo como média 15.

Nota-se que no mês de junho houve um predomínio dos pacientes registrados, que sugere treinamentos e capacitação dos profissionais, a fim de instruir e demonstrar a importância do MEWS para as unidades de internação na prevenção de PCR e/ou por se tratar de um período em que se encontravam internados pacientes com os quadros clínicos mais graves e pacientes mais idosos.

No total foram analisados 101 registros do livro MEWS $>5$, os demais foram excluídos devido à incompletude das informações. Para traçar o perfil epidemiológico dos pacientes, foi verificado o percentual correspondente aos sexos feminino e masculino (Gráfico II).

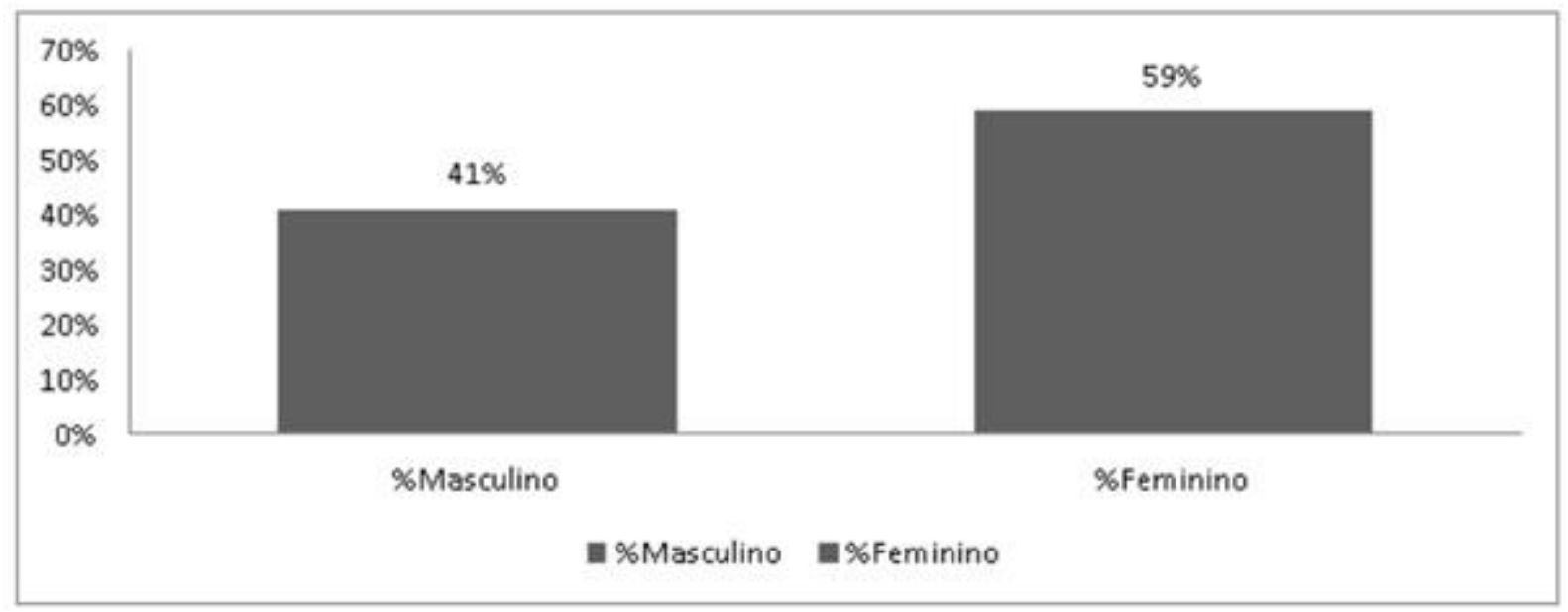

Gráfico II - Percentual de registros analisados do variável sexo.

Observa-se a predominância do sexo feminino com $59 \%$, e $41 \%$ ao sexo masculino nos registros analisados. 


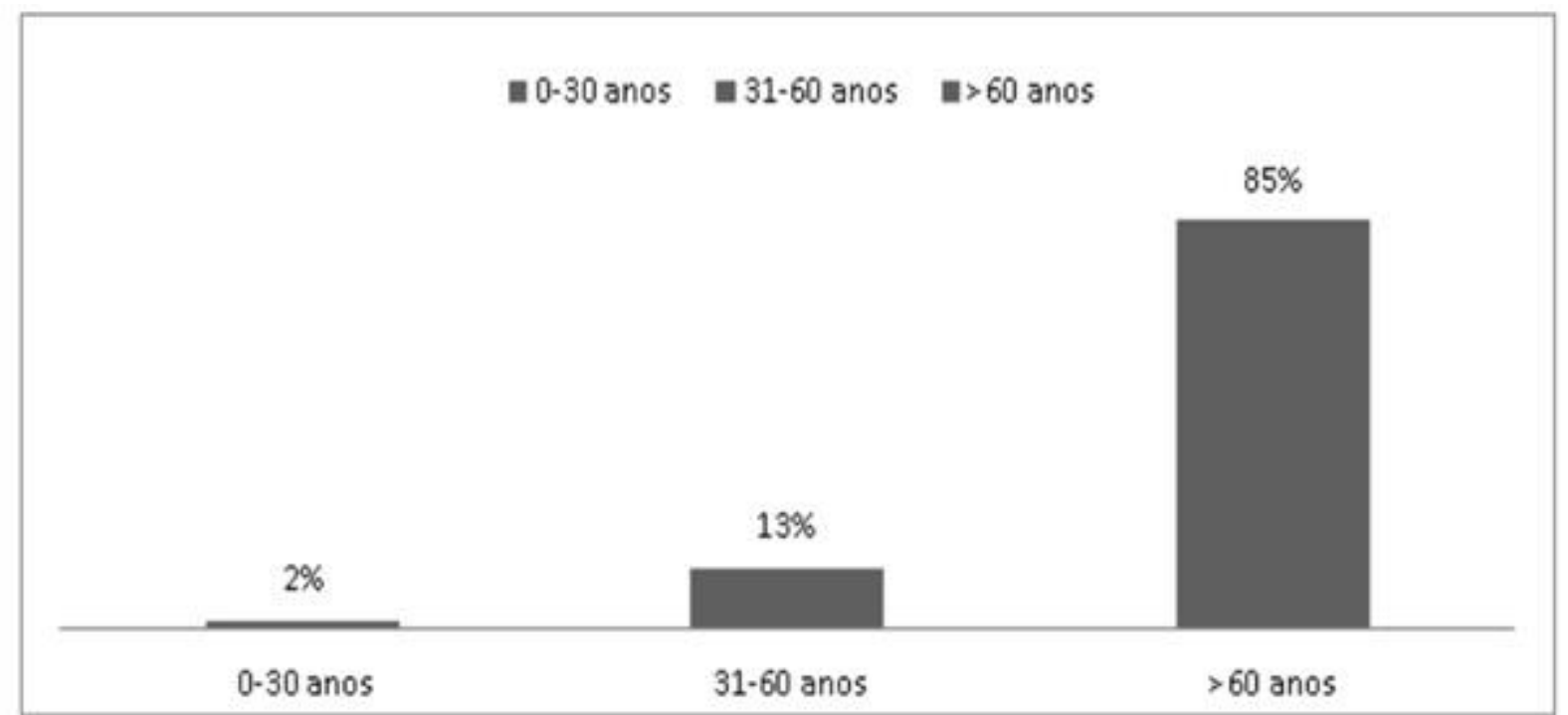

Gráfico III - Percentual de registro da variável idade.

Observa-se um predomínio da faixa etária acima de 60 anos na escala de MEWS, nos registros do livro de Enfermagem. Isto se deve ao fato de que o hospital em estudo é referência em geriatria, portanto atende uma maior quantidade de pacientes idosos.

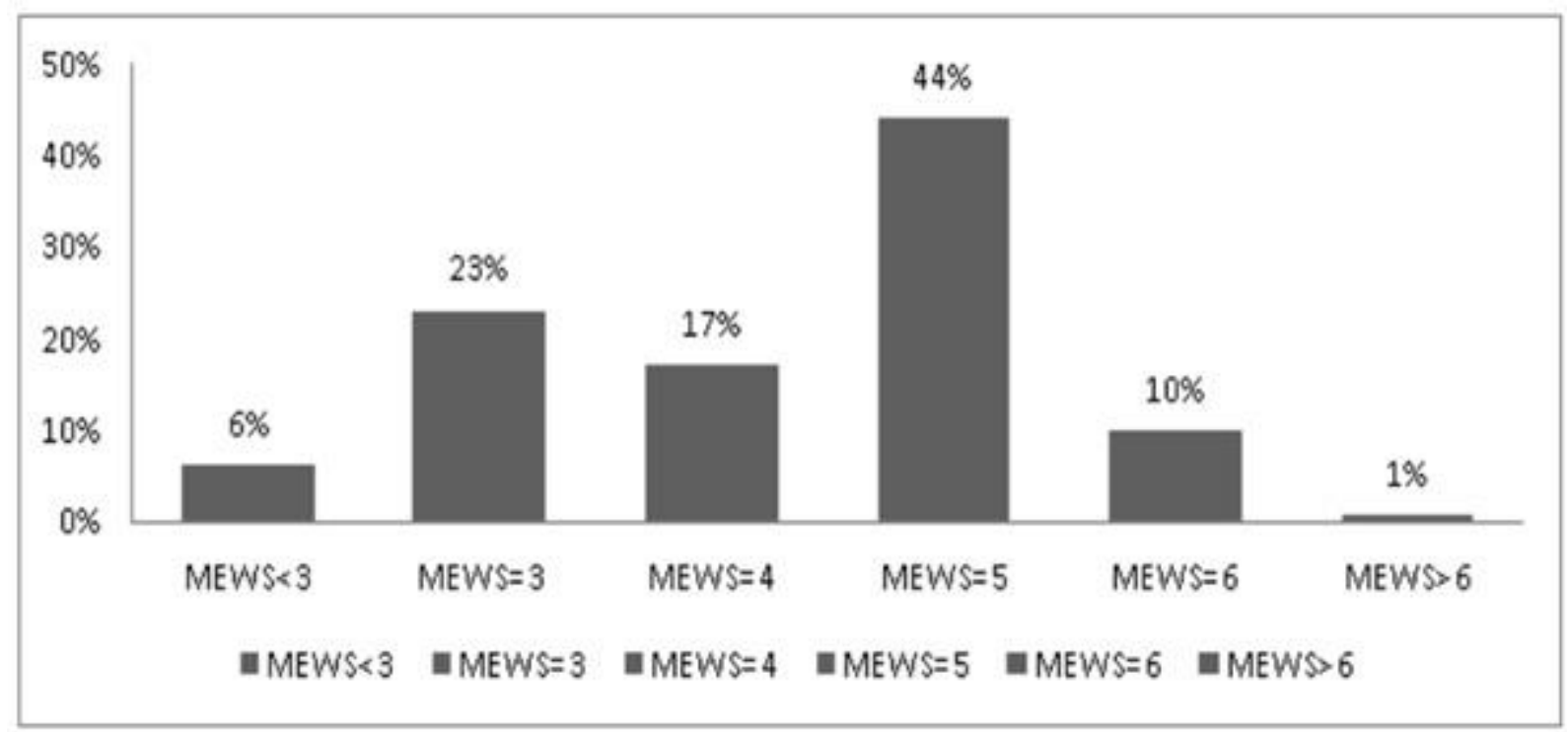

Gráfico IV - Percentual total do valor de MEWS no período de janeiro a julho de 2016.

A partir da análise dos dados do gráfico IV, notou-se que na maior parte dos meses, 0 valor 5 no Score MEWS foi predominante. Provavelmente, devido aos treinamentos realizados com relação ao protocolo, visto que anteriormente no protocolo de MEWS, o valor 5 indicava o ponto de corte para que o médico fosse comunicado, indicando urgência na conduta a ser tomada. Quando o valor era inferior ou igual a 3, o enfermeiro da unidade deveria ser comunicado, e as condutas tomadas de modo a prevenir a deterioração clínica do paciente, nem sempre sendo necessário comunicar o ocorrido ao supervisor de enfermagem ou ao médico. Vale ressaltar que a meta para registro de MEWS $<3$ equivale a $30 \%$. 


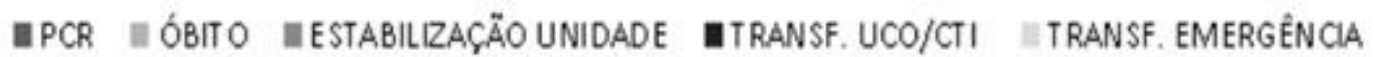

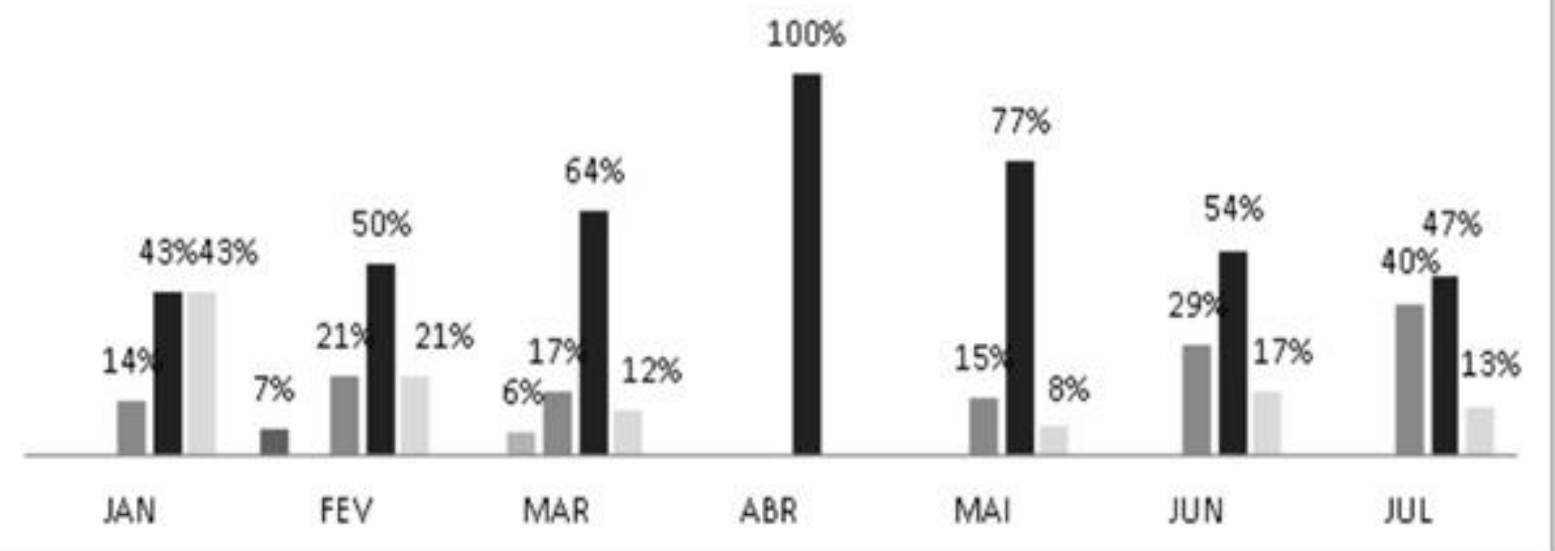

Gráfico V - Percentual mensal dos desfechos registrados no livro de enfermagem do score de MEWS.

De acordo com o gráfico $\mathrm{V}$, nota-se que na maior parte dos meses analisados a Transferência para CTI ou UCO foi predominante: janeiro correspondendo a $43 \%$, percentual idêntico ao referente à Transferência para Emergência (43\%); fevereiro (50\%); março (61\%); abril (100\%); maio (77\%); junho (54\%); julho (47\%).

Houve apenas 1 óbito registrado no mês de março, e uma PCR registrada no mês de fevereiro, denotando um avanço considerável, com relação ao início da implantação do MEWS no referido hospital. Merece destaque que no mês de julho o percentual de estabilização na unidade foi maior, em relação aos outros meses, correspondendo a $40 \%$, indicando uma detecção precoce da deterioração clínica do paciente, proporcionando uma resolução mais rápida do caso.

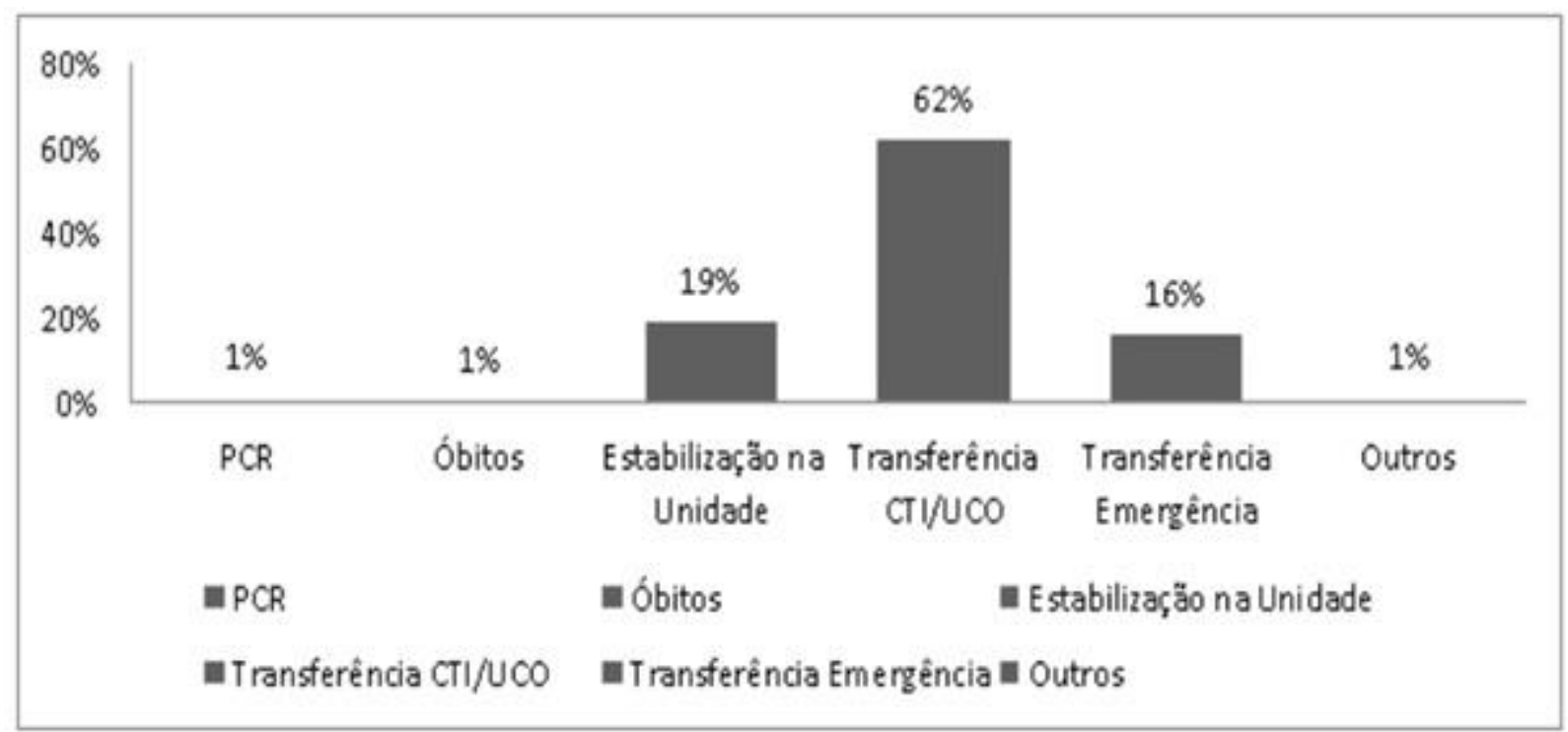

Gráfico VI - Percentual total dos desfechos registrados no livro de enfermagem do score de MEWS.

O gráfico VI mostra que o maior percentual relacionado a desfecho refere-se à Transferência para CTI/UCO (62\%), seguido de Estabilização na Unidade (19\%) e Transferência para Emergência (16\%). A meta do hospital é atingir um percentual de até $98 \%$ somando-se os desfechos referidos acima. 
É importante mencionar que, segundo dados da Comissão de Revisão de Óbitos (CRO) do referido hospital, houve um percentual de melhora de $31,57 \%$ da ocorrência de óbitos em 2016, quando comparado ao ano de 2015, havendo uma redução de mais de cem óbitos.

Discussão

O MEWS é uma escala de alerta baseada em parâmetros fisiológicos que permite identificar precocemente níveis de deterioração clínica do paciente. Conhecer os resultados do protocolo do MEWS se faz necessário para conhecer a realidade do setor, identificar as fragilidades e propor melhorias. Com isso, pode-se prontamente direcionar medidas precoces e mais intensivas para evitar a deterioração clínica desses pacientes, uma vez que há relação direta entre a presença de escore crítico e a crescente morbimortalidade [13]. Entretanto é ressaltada a escassez de estudos, e a discrepância dos resultados nas pesquisas realizadas mostram a utilização do MEWS com o objetivo de aumentar a segurança do paciente e a qualidade da assistência [14].

No hospital em estudo, a implantação do MEWS mostrou a melhora nos registros dos pacientes, após treinamentos e capacitação dos profissionais. O MEWS é uma ferramenta simples aplicado à beira do leito, e pode ser interpretado pelo médico na tentativa de identificar os pacientes de alto risco [15]. Observa-se nos resultados do estudo que houve uma predominância de transferência para unidade de tratamento intensivo. A comissão de revisão de óbitos registrou um percentual de melhora de $31,35 \%$ de ocorrência de óbitos no ano de 2016 comparado com igual período de 2015.

Há relatos em pesquisas que os pacientes admitidos em UTI têm variável de morbimortalidade e geralmente apresentam sinais de alerta alguns dias de sua internação [4]. No estudo publicado por Rocha et al. [13] os pacientes que obtiveram soma igual ou superior a cinco pontos no escore do MEWS foram associados a maior risco de morte e admissão em CTI. Este fato reforça o uso da ferramenta MEWS pelos profissionais de saúde em todas as unidades de internação e emergência, de modo a reconhecer precocemente a deterioração clínica.

O estudo mostra a predominância do valor 5 no escore MEWS, quando o médico era comunicado indicando a urgência na conduta a ser tomada. Enquanto o valor 3 o enfermeiro assumia a responsabilidade de prevenir a deterioração clínica do paciente.

Comenta-se que existe uma forte associação entre a presença de escores críticos $(>3$ pontos) e a deterioração clínica dos pacientes cujos parâmetros já se achavam alterados 72 horas antes da admissão [15].

Verificou-se apenas um estudo brasileiro de 2008 no qual é efetuada a escala de MEWS para avaliar o risco de degradação dos pacientes [15]. No contexto de Portugal é enfocado que foi identificado apenas um estudo no qual foi efetuada a implementação do estudo de alerta precoce EWS de Morgan [16].

Outros estudos também demonstraram que os desfechos (óbito, transferência para CTI) foram significativamente maiores no grupo avaliado pelo MEWS [13], o que não difere de forma significativa quando comparado à nossa pesquisa, com exceção da variável óbito. Conforme resultados, descritos no gráfico $\mathrm{VI}$, o percentual de transferências para as unidades fechadas foram significativamente maiores comparado com as outras variáveis. Sendo assim, o uso do MEWS pode representar um incentivo para a célere identificação dos pacientes críticos nas unidades de internação que requerem atenção rápida e possível admissão na unidade de tratamento intensivo CTI/UCO [13].

\section{Conclusão}

O estudo mostra a efetividade da assistência ao paciente após a utilização do MEWS, com a melhora dos registros, na avaliação de deterioração clínica dos pacientes, assim como a ocorrência de óbitos na unidade.

É possível observar que direciona um seguimento continuado dos pacientes, denunciando que aqueles com os escores alterados e com aumento progressivo necessitam de maior atenção pela equipe responsável, posto que há evidências de que a intervenção precoce pode melhorar o desfecho evolutivo.

A partir dos resultados obtidos no estudo, observa-se que a implantação do Score de Alerta Precoce Modificado (MEWS), no hospital em estudo, tem se mostrado bastante eficaz, sendo uma excelente ferramenta de avaliação e prevenção da deterioração clínica hospitalar, 
minimizando a ocorrência de PCR e óbito. Contudo, diante da escassez de estudos, percebese a necessidade de que sejam realizadas pesquisas sob essa temática, a fim de que esta ferramenta seja mais explorada, para haver resultados máximos e para que se perceba a importância da sua aplicação nas instituições de saúde, favorecendo estratégias que visem à qualidade da assistência e segurança dos pacientes.

1. Ribas EO. Avaliação do processo de implementação de um novo modelo de abordagem assistencial nas unidades de internação do hospital Mãe de Deus [TCC]. Porto Alegre: UFRS; 2006. p.38.

2. Silva $A B$, Machado RC. Elaboração de guia teórico de atendimento em parada cardiorrespiratória para enfermeiros. Rev Rene 2013;14(4):1014-21.

3. Lafetá AFM, Paula BP, Lima CA, Leite LES, Paiva PA, Leão HM et al. Suporte avançado de vida na parada cardiorrespiratória: aspectos teóricos e assistenciais. Rev da Universidade Vale do Rio Verde 2015;13(1):653-63.

4. Santos LP, Rodrigues NAM, Bezerra ALD, Sousa MNA, Feitosa ANA, Assis EV. Parada cardiorrespiratória: principais desafios vivenciados pela enfermagem no serviço de urgência e emergência. Rev Interdisciplinar em Saúde 2016;3(1):35-53.

5. Gonzalez MM, Timerman S, Gianotto-Oliveira R, Polastri TF, Canesin MF, Canesin MF et al. I Diretriz de ressuscitação cardiopulmonar e cuidados cardiovasculares de emergência da Sociedade Brasileira de Cardiologia: resumo executivo. Arq Bras Cardiol 2013;100(2):105-13.

6. Gardner-Thorpe J, Love N, Wrightson J, Walsh S, Keeling N. The value of Modified Early Warning Score (MEWS) in surgical in-patients: a prospective observational study. Ann R Coll Surg Engl 2006;88:571-5.

7. Wang AY, Fanq CC, Chen SC, Tsai SH, Kao WF. Periarrest modified early warning score (mews) predicts the outcome of in-hospital Cardiac arrest. J Formos Med Assoc 2016;115:76-82.

8. Quinton S. Adult modified early warning score (MEWS) policy \& escalation pathway. England: Heart of England NHS Foundation Trust; 2009.

9. Goleby WH, Thompson F, Maunder B, De Monte S, Franks C, et al. Modified early warning score (MEWS), escalation and ISBAR. Queensland Government Health 2012;1:1-5.

10. Hammond NE, Spooner AJ, Barnett AG, Corley A, Brown P, Fraser JF. The effect of implementing a modified early warning scoring (MEWS) system on the adequacy of vital sign documentation. Australian Critical Care 2013;26:18-22.

11. Creswell JW. Projeto de pesquisa: métodos qualitativo, quantitativo e misto. Traduzido por: Lopes M. Porto Alegre: Artmed; 2010. p.296.

12. Gil AC. Como elaborar projetos de pesquisa. 4. ed. São Paulo: Atlas; 2002.

13. Rocha TF, Neves JG, Viegas K. Escore de alerta precoce modificado: avaliação de pacientes traumáticos. Rev Bras Enferm 2016;69(5):850-5.

14. Rios S, Silene KABAM, Rocha FM. Análise do Protocolo de deterioração clínica baseado no MEWS- Trabalho apresentado no XIII Encontro de Enfermeiros de Hospitais de Ensino de São Paulo. Unicamp, Campinas/SP; 2016.

15. Tavares RC, Vieira AS, Uchoa LV, Peixoto Junior AA, Menezes FA. Validação de um escore de alerta precoce pré-admissão na Unidade de Terapia Intensiva. Rev Bras Ter Intensiva 2008;20(2):124-7.

16. Luis L. Validação e aplicação dos SPAP VIEWS e MEWS em Portugal [Dissertação]. Algarve: Escola Superior de Tecnologia da Saúde de Lisboa, Escola Superior de Saúde da Universidade do Algarve; 2014. 